\title{
Tribological properties of conductive lubricating greases
}

\author{
Xiaoqiang FAN ${ }^{1,2}$, Yanqiu XIA ${ }^{1, *}$, Liping WANG ${ }^{1}$ \\ ${ }^{I}$ State Key Laboratory of Solid Lubrication,Lanzhou Institute of Chemical Physics, Chinese Academy of Sciences, Lanzhou, 730000, China \\ ${ }^{2}$ University of Chinese Academy of Sciences, Beijing100039, China \\ Received: 26 May 2014 / Revised: 14 July 2014 / Accepted: 14 August 2014 \\ (C) The author(s) 2014. This article is published with open access at Springerlink.com
}

\begin{abstract}
Three kinds of new conductive lubricating greases were prepared using lithium ionic liquids as the base oil and the polytetrafluoroethylene (PTFE) as the thickener. These lithium ionic liquids ([Li(PEG)X]) were obtained by blending lithium salts $\left(\mathrm{LiBF}_{4}, \mathrm{LiPF}_{6}\right.$ and $\left.\mathrm{LiNTf}_{2}\right)$ with poly(ethylene glycol) (PEG) because lithium salts have an extremely high solubility in PEG. The conductivities and contact resistances of the prepared lubricating greases were investigated using the DDSJ-308A conductivity meter and the reciprocating ballon-disk UMT-2MT sliding tester. In addition, their tribological properties were investigated in detail. Scanning electron microscopy and X-ray photoelectron spectroscopy were employed to explore the friction mechanisms. The results suggest that the prepared lubricating greases have high conductivities and excellent tribological properties. The high conductivities are attributed to ion diffusion or migration of the lithium ionic liquids with an external electric field, and the excellent tribological properties depend on the formation of boundary protective films.
\end{abstract}

Keywords: ionic liquids; grease; conductivity; tribology

\section{Introduction}

Grease lubricants not only reduce friction and wear in mechanical systems but also play a significant role in saving energy and reducing $\mathrm{CO}_{2}$ emission by improving the lubrication efficiency and prolonging the service life of machines. However, the limited service life of grease lubricants, which is their primary disadvantage, restricts their application, and often determines the service life of mechanical systems [1,2]. Thus, developing greases that combine the characteristics of lower friction and wear, and a longer lifetime under boundary conditions would be a significant innovation.

Solid lubricants, such as graphite and molybdenum disulfide $\left(\mathrm{MoS}_{2}\right)$, have been studied over the past several decades to improve their tribological properties and solve lubrication problems. These lubricants' excellent tribological performances are related to their

* Corresponding author: Yanqiu XIA.

E-mail: xiayanqiu@yahoo.com structures and chemical properties because they can form a smooth protective film on sliding surfaces $[3,4]$. However, the insolubility and poor dispersion of graphite and $\mathrm{MoS}_{2}$ limit their application in fluid lubricants, and their effectiveness as fluid lubricant additives has been questioned because fluid lubricants containing well-dispersed graphite and $\mathrm{MoS}_{2}$ particles also contain dispersants or surface modifiers that could prevent the particles from depositing on sliding surfaces.

Ionic liquids (ILs) were reported as novel versatile lubricants in 2001 and have attracted considerable attention in the lubrication field due to their excellent lubrication properties [5]. ILs are composed of an organic cation and a weakly coordinating inorganic anion with melting points lower than room temperature [6,7]. ILs possess a combination of unique characteristics, including negligible volatility, nonflammability, high thermal stability, low melting point, and high conductivity; these have led to intense research and a wide range of applications, including 
electrochemistry, organic synthesis, catalysis, and photochemistry [8-13]. It is well known that these characteristics of ILs are precisely what highperformance lubricants require. In recent years, ILs have been investigated as versatile lubricants for steel/ steel, steel/aluminum, steel/copper, and surface coating/ steel contacts [14-19]. Feng and Xia [20] found that 1,3dialkyl imidazolium ILs as lubricants for Ti-DLC/steel contacts have excellent friction-reducing properties and keep the friction coefficient at a relatively stable value ( 0.07-0.06), which approximately $47 \%$ lower than perfluoropolyether (PFPE). Cai et al. [21] reported that imidazolium ILs with a benzotriazole group added to polyurea grease for steel/steel contacts can reduce the wear by approximately 12 times, so ILs as lubricant additives have excellent friction reduction and antiwear properties.

Most previous studies have been confined to using expensive imidazolium ILs as lubricants, while different kinds of ILs could be obtained by varying the cation or anion and their combinations [22]. Fan et al. [23] found a novel method of in situ formation of ILs on the basis of the high solubility of lithium salt in some synthetic oils. Given the findings that solid lithium salts can easily dissolve in synthetic oils and form novel ILs, the aim of our study is to investigate this kind of IL and to evaluate it tribological performance.

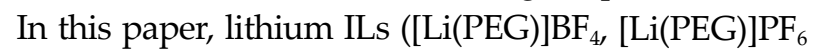
and $[\mathrm{Li}(\mathrm{PEG})] \mathrm{NTf}_{2}$ ) can be easily obtained by dissolving lithium salts $\left(\mathrm{LiBF}_{4}, \mathrm{LiPF}_{6}\right.$ and $\left.\mathrm{LiNTf}_{2}\right)$ in poly(ethylene glycol) (PEG) because lithium salts are highly soluble in PEG. The conductive lubricating greases were prepared using the lithium ILs as a base oil, polytetrafluoroethylene (PTFE) as a thickener. The greases' physicochemical and tribological properties were evaluated in detail, and the tribo-surfaces were examined using scanning electron microscopy (SEM) and X-ray photoelectron spectroscopy (XPS) in order to explore the mechanism of friction and wear under boundary lubrication.

\section{Experimental procedures}

\subsection{Materials}

PEG used in this paper was purchased from Sinopharm Chemical Reagent Co. Ltd. The average molecular weight was between 190 and $210 \mathrm{~g} / \mathrm{mol}$. The lithium salts $\left(\mathrm{LiBF}_{4}, 99 \mathrm{wt} \%\right.$; $\mathrm{LiPF}_{6}, 99 \mathrm{wt} \%$; $\left.\mathrm{LiNTf}_{2}, 99 \mathrm{wt} \%\right)$ were commercially obtained from Shanghai Energy Lithium Industrial Company. Acetone and PTFE micro-powder were also commercially obtained. The grain size of the PTFE micro-powder was approximately $4 \mu \mathrm{m}$ (Dyneon. ${ }^{\mathrm{TM}}$ TF9207), and its density was $2.2 \mathrm{~g} / \mathrm{cm}^{3}$. All chemical reagents were of analytical grade and used without further purification.

\subsection{Preparation and characterization of the lubricating greases}

The lubricating greases were prepared according to the following procedures. A base oil of $83 \mathrm{wt} \%$ was added into its corresponding vessel stirred. Then, PTFE of $17 \mathrm{wt} \%$ used as a thickener, was slowly added to the vessel during vigorous stirring. When the base oil and thickener were mixed uniformly, acetone of about half of the total mass of the thickener was added dropwise to ensure that the thickener was well dispersed in the base oils. After continued stirring for about $30 \mathrm{~min}$, the mixture was heated to $80{ }^{\circ} \mathrm{C}$ and maintained at this temperature for about $30 \mathrm{~min}$ to remove the acetone. When the mixture was cooled to room temperature, it was introduced to a roller and was ground and homogenized by three close rollers that rotated in opposite directions. Finally, the lubricating greases (PEG grease, $[\mathrm{Li}(\mathrm{PEG})] \mathrm{BF}_{4}$ grease, $[\mathrm{Li}(\mathrm{PEG})] \mathrm{PF}_{6}$ grease, and $[\mathrm{Li}(\mathrm{PEG})] \mathrm{NTf}_{2}$ grease) were obtained after three separate fine grinding and homogenization steps in the three-roller mill.

The dropping point of the lubricating greases (wide temperature range) and the cone penetration (lubricating grease and petrolatum) were determined and characterized according to the national standards GB/T 3498 and GB/T 269, which are similar to ASTM D2265 and ASTM D1403. The copper strip tests (corrosiveness to copper) of the lubricating greases were performed by the national standard GB/T 732687. The conductivities of the lubricating greases were measured at $25^{\circ} \mathrm{C}$ by the DDSJ-308A conductivity meter made by Shanghai INESA Scientific Instrument Co. Ltd. The colloid stability of the lubricating greases was measured by the national petrochemical industry standards SH/T 0324-92. Thermogravimetric analysis (TGA) of the lubricating greases was carried out on 
an STA 449C simultaneous thermal analyzer made by Netzsch-Gerätebau $\mathrm{GmbH}$ at a heating rate of $10{ }^{\circ} \mathrm{C} / \mathrm{min}$ in flowing air.

\subsection{Resistance test during sliding process}

The surface contact resistance value of the lubricating greases during the friction process was tested on the reciprocating ball-on-disk UMT-2MT sliding tester at ambient temperature. Commercially available AISI steel balls with a diameter of $6 \mathrm{~mm}$ were used as the stationary upper counterparts against the lower specimen (single-crystal Si(100) wafers), which was mounted onto a reciprocating table with a traveling distance of $5 \mathrm{~mm}$. The friction tests were conducted at sliding frequency of $5 \mathrm{~Hz}$, applied load of $10 \mathrm{~N}$, a test duration of $60 \mathrm{~min}$.

\subsection{Friction and wear test}

The tribological properties of the lubricating greases were evaluated on an Optimal SRV-I reciprocation friction and wear tester with a ball-on-block configuration. The upper ball (diameter of $10 \mathrm{~mm}$, AISI 52100 steel, hardness $710 \mathrm{HV}$ ) slides reciprocally at an amplitude of $1 \mathrm{~mm}$ against the stationary lower steel disks (AISI 52100 steel, $\Phi 24 \mathrm{~mm} \times 7.9 \mathrm{~mm}$ with the hardness of $\sim 730-764 \mathrm{HV}$ ). All the tests were conducted at applied loads range from 200 to $800 \mathrm{~N}$ with the requency of $30 \mathrm{~Hz}$ and frequencies range from 10 to $50 \mathrm{~Hz}$ with a constant applied load of $300 \mathrm{~N}$ at room temperature and each test lasted for $30 \mathrm{~min}$. About $1 \mathrm{~g}$ of grease was introduced to the ball-disc contact area and the friction coefficient was recorded automatically by a computer connected to the Optimal SRV-I tester. The wear loss of the lower disks was measured using a MicroXAM-3D surface mapping microscope profilometer. The friction tests were repeated three times for each sample under the same testing condition to obtain the average friction coefficient and wear volume.

\subsection{Characterization of the worn surface}

The morphologies of the wear surfaces and the binding energies of some typical elements on the worn surfaces were analyzed by a JEM-5600LV scanning electron microscope (JEOL, Japan) and a PHI-5702 multifunctional X-ray photoelectron spectroscope (American
Institute of Physics Electronics Company, America) using K-Alpha radiation as the excitation source. The binding energies of the target elements were determined at a pass energy of $29.3 \mathrm{eV}$, with a resolution of about $\pm 0.3 \mathrm{eV}$, using the binding energy of contaminated carbon (C1s: $284.8 \mathrm{eV})$ as a reference. Prior to characterization, the steel disks were cleaned ultrasonically several times in baths of acetone and dried with pure nitrogen for surface analysis.

\section{Results and discussion}

\subsection{FTIR results of the lithium ionic liquids}

Fourier transform infrared analysis was conducted to investigate the functional groups of lithium ILs. As shown in Fig. 1, the PEG has the characteristic peaks of $-\mathrm{CH}_{2}-\mathrm{CH}_{2}-$ and $-\mathrm{CH}_{2}-\mathrm{O}-\mathrm{CH}_{2}-$ at about $2,858 \mathrm{~cm}^{-1}$ and $1,124 \mathrm{~cm}^{-1}$ [24]. The $\mathrm{BF}_{4}^{-}$peak of [Li(PEG)]BF ${ }_{4}$ appears at $1,032 \mathrm{~cm}^{-1}$, the $\mathrm{PF}_{6}^{-}$sharp peak of $[\mathrm{Li}(\mathrm{PEG})] \mathrm{PF}_{6}$ is at $842 \mathrm{~cm}^{-1}$ and the $\mathrm{NTf}_{2}^{-}$peaks of [Li(PEG)]NTf $\mathrm{Nare}_{2}$ at $639 \mathrm{~cm}^{-1}$ and $1,250 \mathrm{~cm}^{-1}$. Through the donation of lone pairs from an oxygen atom of PEG to the $\mathrm{Li}^{+}$cation, a weakly Lewis acidic complex cation $[\mathrm{Li}(\mathrm{PEG})]^{+}$can be generated, which can form new ILs ([Li(PEG)]X) with the weakly Lewis basic anions $\left(\mathrm{BF}_{4}^{-}, \mathrm{PF}_{6}^{-}\right.$and $\left.\mathrm{NTf}_{2}{ }^{-}\right)$ of lithium salts $[25,26]$.

\subsection{Physical properties of the prepared lubricating greases}

The physical properties of the base oils and prepared lubricating greases are listed in Tables 1 and 2, respectively. As shown in Table 2, the lithium IL grease has high dropping point $\left(>200^{\circ} \mathrm{C}\right)$ and good conductivity $\left(>130 \mu \mathrm{S} \cdot \mathrm{cm}^{-1}\right)$. The lithium IL greases can significantly improve the colloid stability of the lubricating grease, while their anti-corrosion properties are not as good as the PEG grease. Therefore, the lithium ILs have an obvious effect on the stability and electrical conductivity of the lubricating grease. The PEG grease is regarded as having no conductivity $\left(0 \mu \mathrm{S} \cdot \mathrm{cm}^{-1}\right)$, so the conductivity of the lithium IL greases is attributed to the nature of lithium ILs. Figure 2 shows the TGA curves of the lubricating greases. The PEG grease and lithium IL greases have nearly the same decomposition temperature which suggests that they have good thermal stability. 

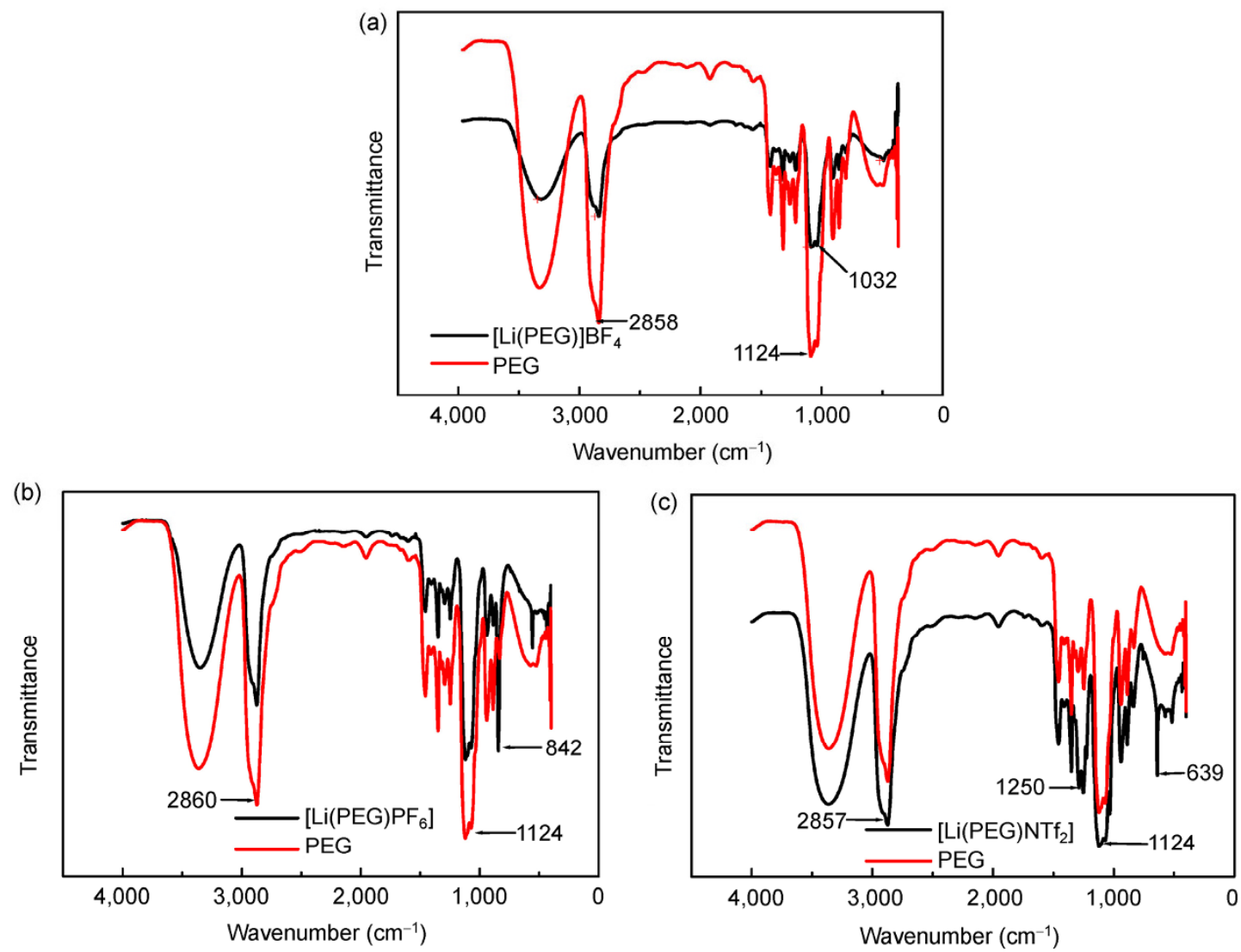

Fig. 1 Fourier transform infrared analysis spectra of the lithium-based ionic liquids.

Table 1 Physical properties of base oils.

\begin{tabular}{ccccc}
\hline $\begin{array}{c}\text { Code } \\
(\text { Base Oil })\end{array}$ & $\begin{array}{c}\text { Conductivity } \\
\left(\mu \mathrm{S} \cdot \mathrm{cm}^{-1}\right)\end{array}$ & \multicolumn{2}{c}{ Kinematic viscosity $\left(\mathrm{mm}^{2} \cdot \mathrm{s}^{-1}\right)$} & $\begin{array}{c}\text { Density } \\
\left(\mathrm{g} \cdot \mathrm{ml}^{-1}\right) \mathrm{at} 25^{\circ} \mathrm{C}\end{array}$ \\
\hline PEG & 0 & $40^{\circ} \mathrm{C}$ & $100^{\circ} \mathrm{C}$ & 3.9 \\
{$[\mathrm{Li}(\mathrm{PEG})] \mathrm{BF}_{4}$} & 588 & 22.4 & 5.6 & 1.125 \\
{$[\mathrm{Li}(\mathrm{PEG})] \mathrm{PF}_{6}$} & 364 & 39.8 & 5.6 & 1.19 \\
{$[\mathrm{Li}(\mathrm{PEG})] \mathrm{NTf}_{2}$} & 416 & 41.0 & 5.5 & 1.18 \\
\hline
\end{tabular}

Table 2 Physical properties of the synthesized lubricating greases.

\begin{tabular}{cccccc}
\hline Sample (grease) & $\begin{array}{c}\text { Dropping point } \\
\left({ }^{\circ} \mathrm{C}\right)\end{array}$ & $\begin{array}{c}\text { Penetration } \\
(1 / 4 \mathrm{~mm})\end{array}$ & $\begin{array}{c}\text { Copper corrosion } \\
\left(\mathrm{T} 2 \text { copper, } 100^{\circ} \mathrm{C}, 24 \mathrm{~h}\right)\end{array}$ & $\begin{array}{c}\text { Conductivity, } \sigma \\
\left(\mu \mathrm{S} \cdot \mathrm{cm}^{-1}\right)\end{array}$ & $\begin{array}{c}\text { Colloid stability } \\
(w / w \%)\end{array}$ \\
\hline PEG & 189 & 99 & $1 \mathrm{a}$ & 0 & 5.07 \\
{$[\mathrm{Li}(\mathrm{PEG})] \mathrm{BF}_{4}$} & 211 & 83 & $1 \mathrm{~b}$ & 289 & 2.07 \\
{$[\mathrm{Li}(\mathrm{PEG})] \mathrm{PF}_{6}$} & 202 & 78 & $1 \mathrm{~b}$ & 136 & 1.41 \\
{$[\mathrm{Li}(\mathrm{PEG})] \mathrm{NTf}_{2}$} & 223 & 80 & $2 \mathrm{c}$ & 161 & 3.03 \\
\hline
\end{tabular}

\subsection{Resistance results}

To investigate the resistance values of the lithium IL lubricating greases during the sliding process, their friction coefficient and contact resistance were simultaneously measured on the reciprocating ballon-disk UMT-2MT sliding tester and the results are shown in Fig. 3. The [Li(PEG)]PF, $\mathrm{PF}_{6}[\mathrm{Pi}(\mathrm{PEG})] \mathrm{NTf}_{2}$ and 


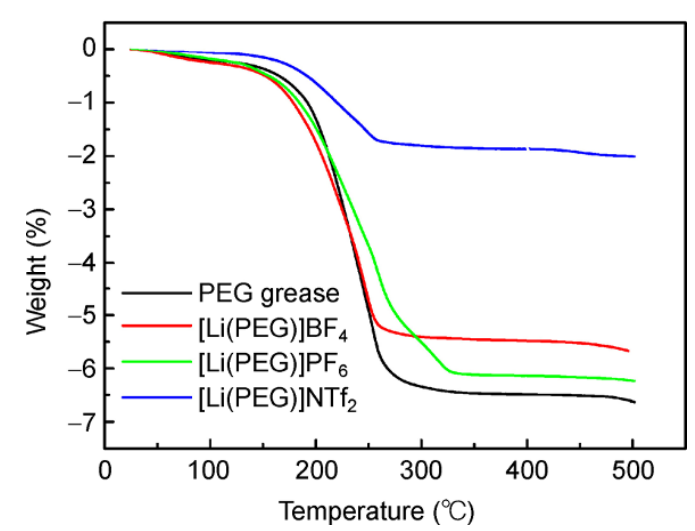

Fig. 2 Thermo-gravimetric analysis curves of the PEG grease, $[\mathrm{Li}(\mathrm{PEG})] \mathrm{BF}_{4}$ grease, $[\mathrm{Li}(\mathrm{PEG})] \mathrm{PF}_{6}$ grease and $[\mathrm{Li}(\mathrm{PEG})] \mathrm{NTf}_{2}$ grease.
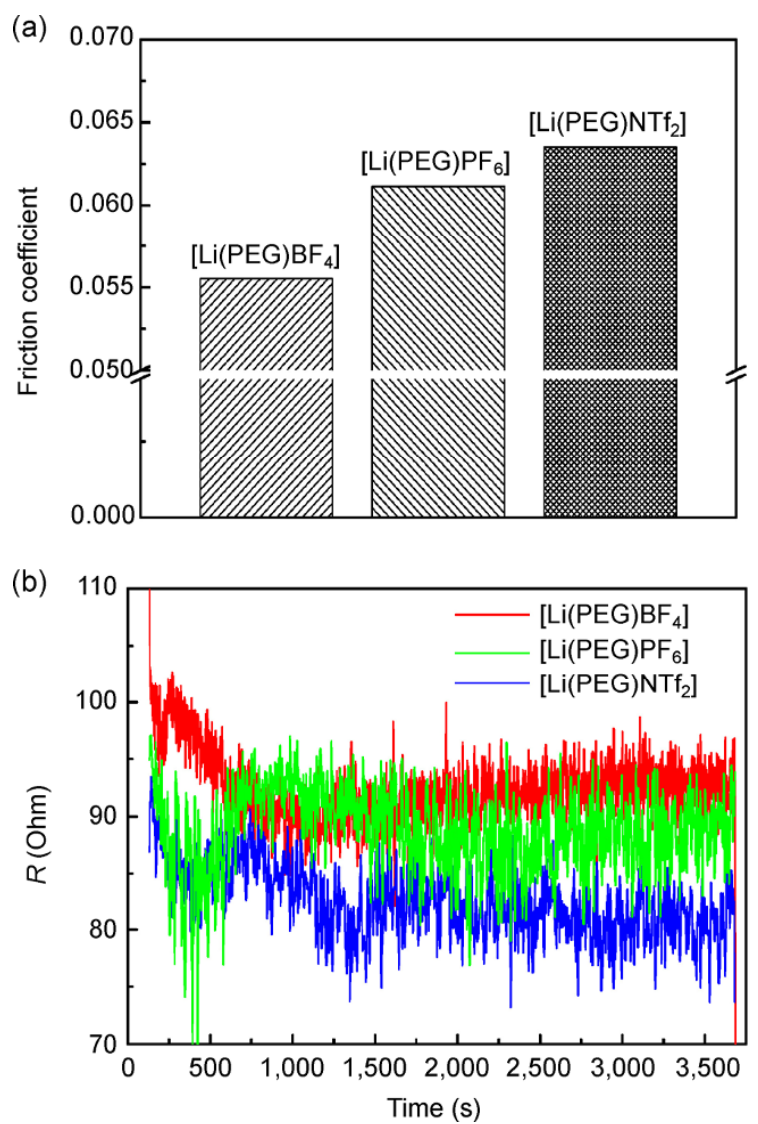

Fig. 3 The friction coefficient (a) and resistance change (b) lubrication with $[\mathrm{Li}(\mathrm{PEG})] \mathrm{BF}_{4}$ grease, $[\mathrm{Li}(\mathrm{PEG})] \mathrm{PF}_{6}$ grease and $[\mathrm{Li}(\mathrm{PEG})] \mathrm{NTf}_{2}$ grease on monocrystalline silicon.

[Li(PEG) $] \mathrm{BF}_{4}$ greases show a low friction coefficient $(\sim 0.06)$ and low resistance $(\sim 90 \mathrm{Ohm})$. The conductivities of the lithium IL greases are attributed to the diffusion or migration of an organic cation and a weakly coordinating inorganic anion. The ion diffusion and migration originate from cation-anion interactions, which are mainly determined by the distance between the cations and anions [27]. Therefore, the lithium ILs have a high conductivity because of the reduced cation-anion interactions. The contact resistance tests provided real-time information about the formation of surface films because the formation of physical adsorption films and tribo-chemical reaction films acted as either an insulating barrier or an electrical layer carrying current. In addition, the stable resistance value could indicate that the lithium IL greases provide excellent sealing that may prevent side flow and reduce lubricant starvation. Reducing starvation plays a major role in providing a long grease service life.

\subsection{Friction and wear results}

The Optimal SRV-I tester was employed to investigate the performance of the prepared lubricating greases. Figure 4 compares the friction coefficient and wear volume for the PEG grease and lithium IL greases. As shown in Figs. 4(a) and 4(c), when the frequency reached $50 \mathrm{~Hz}$, the PEG grease caused a seizure phenomenon and lost its lubrication effect under high-velocity sliding, while the $\left[\mathrm{Li}(\mathrm{PEG}) \mathrm{BF}_{4}\right.$ and $[\mathrm{Li}(\mathrm{PEG})] \mathrm{PF}_{6}$ greases exhibited consistent and lower friction coefficients $(<0.09)$ throughout the tests. This means that at high and low contact pressures the release of lithium ILs from the grease was effective and played an important role in lubrication. The friction coefficient with the lithium IL greases was 1.3 times lower than that with the PEG grease and was stable at low and high speeds and loads, which suggests that the lithium IL greases have an excellent load-bearing capacity $(>800 \mathrm{~N})$ and a low friction behavior.

Figures 4(b) and 4(d) show the wear volumes of the steel disks lubricated by the prepared greases in order to evaluate their antiwear property. The wear volume of the PEG grease is 7.5 times more than that of the lithium IL greases. The lithium IL greases show a much better antiwear performance.

In the past few years, our laboratory has done a great deal of research on using traditional ILs as lubricants. The polyurea grease containing $1.0 \mathrm{wt} \%$ neat IL has a low friction coefficient $(\sim 0.123-0.138)$ and results in low wear volume $\left(\sim 10^{-5} \mathrm{~mm}^{3}\right)$ [28]. Using alkylimidazolium 

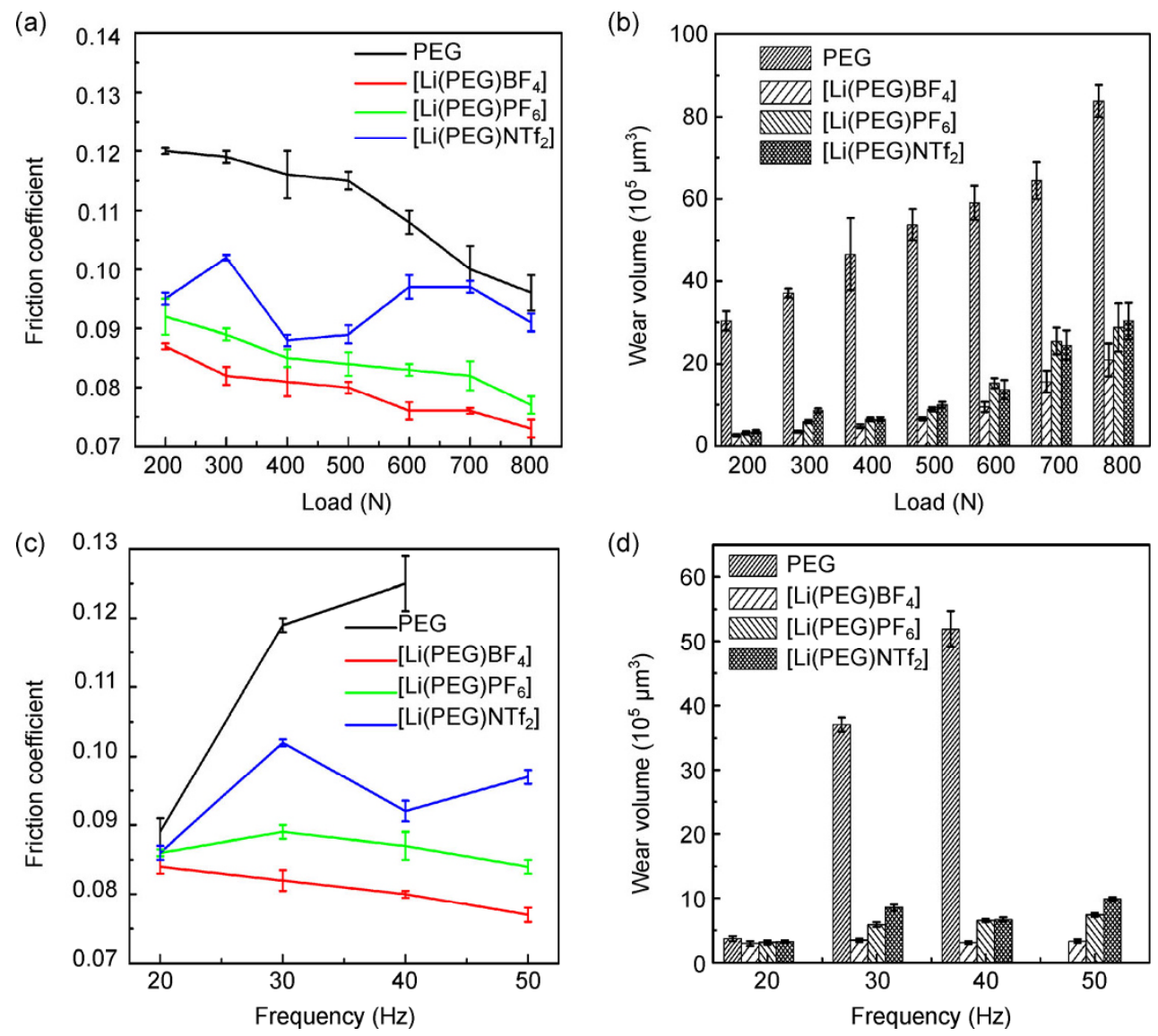

Fig. 4 The friction coefficient $(\mathrm{a}, \mathrm{c})$ and wear volume $(\mathrm{b}, \mathrm{d})$ under the lubrication with PEG grease, $[\mathrm{Li}(\mathrm{PEG})] \mathrm{BF} \mathrm{Brease}_{4}[\mathrm{Li}(\mathrm{PEG})] \mathrm{PF}_{6}$ grease, $[\mathrm{Li}(\mathrm{PEG})] \mathrm{NTf}_{2}$ grease at room temperature and $30 \mathrm{~min}$.

hexafluorophosphates, tetrafluoroborate, and bis(trifluoromethylsulfonyl)-imide as lubricants for the steel/steel contact shows good tribological behavior (Cof $<0.8$, wear volume: $\sim 10^{-5}-10^{-4} \mathrm{~mm}^{3}$ ) [29]. Comparing the lubrication properties of the lithium ILs with those of neat ILs, the lithium ILs have the same excellent lubrication performance, and the prepared lubricating greases using lithium ILs as a base oil are superior to other lubricating grease containing neat ILs in terms of the friction reduction ability and loadcarrying capacity [30]. Therefore, the results showed that the lithium ILs lubricating greases have excellent friction reducing and antiwear properties, which suggests that they have a longer service life.

\subsection{Characterization and analysis of the worn surfaces}

The morphologies of the worn surfaces lubricated with the lubricating greases at $300 \mathrm{~N}, 20 \mathrm{~Hz}$, sliding for $30 \mathrm{~min}$, and ambient temperature are shown in Fig. 5. All of the SEM images were obtained under the same conditions. The worn surfaces of the steel disk lubricated by the PEG grease showed much wider and deeper wear scars than the surfaces lubricated with the lithium IL greases. The wear scars of the steel disks lubricated by $\left[\mathrm{Li}(\mathrm{PEG}) \mathrm{BF}_{4}\right.$ and $\left[\mathrm{Li}(\mathrm{PEG}) \mathrm{PF}_{6}\right.$ greases were relatively shallow, and scuffing was greatly alleviated. The worn surfaces lubricated by the $[\mathrm{Li}(\mathrm{PEG})] \mathrm{NTf}_{2}$ grease showed relatively shallow grooves with many corrosion spots. The corresponding 3D optical microscopic images are also shown in Fig. 5 and further confirm the amount of wear of the steel disks lubricated with the greases. The results of the experiment clearly showed that the lithium greases possess much better excellent antiwear performance than the PEG grease.

The formation of lubricating and protective films on the sliding surface can be further confirmed by 

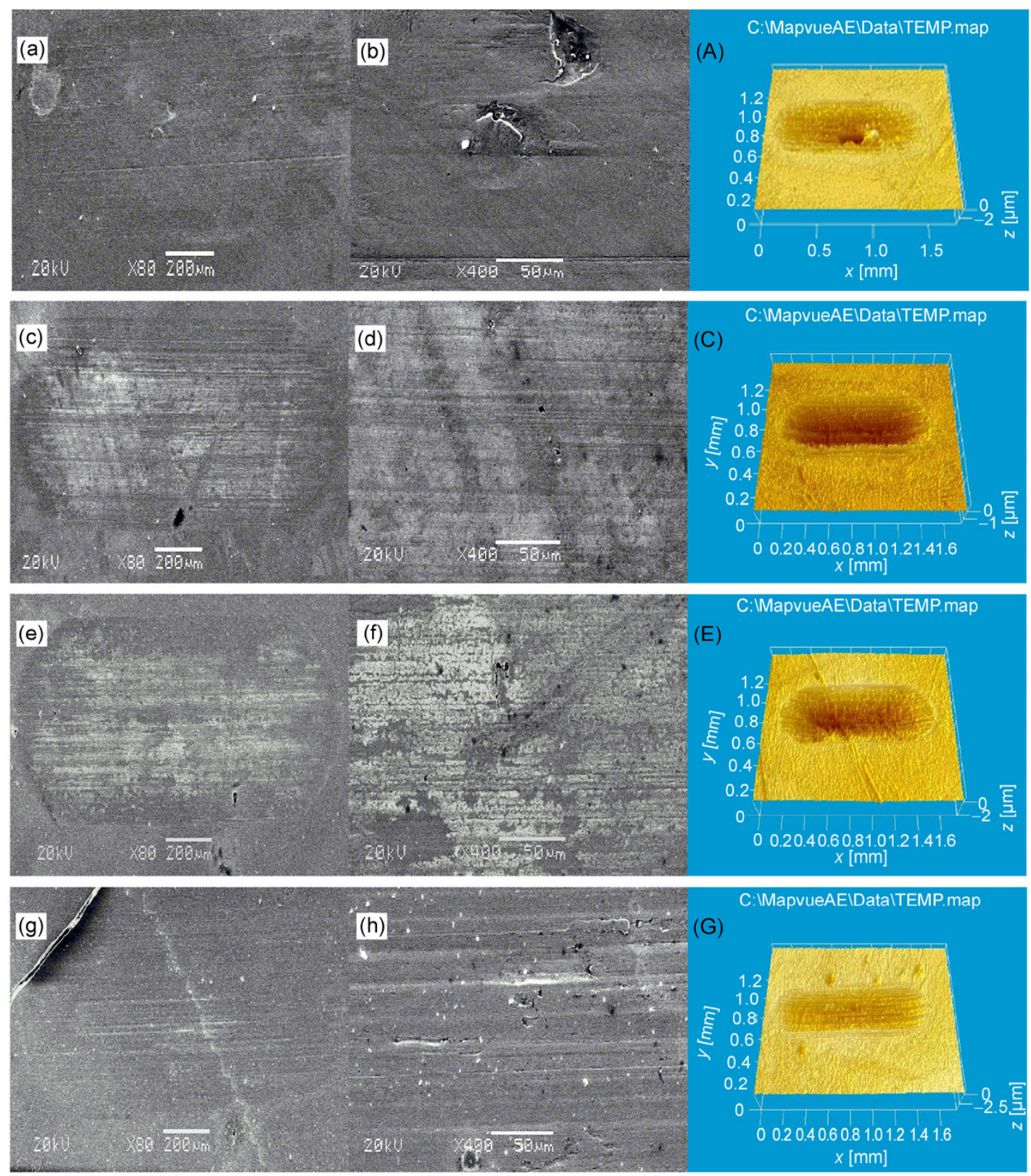

Fig. 5 Scanning electron microscope morphologies and 3D optical microscopic images of the worn surfaces lubricated by (a, b, A) PEG grease, $(\mathrm{c}, \mathrm{d}, \mathrm{C})[\mathrm{Li}(\mathrm{PEG})] \mathrm{BF}_{4}$ grease, $(\mathrm{e}, \mathrm{f}, \mathrm{E})[\mathrm{Li}(\mathrm{PEG})] \mathrm{PF}_{6}$ grease and $(\mathrm{g}, \mathrm{h}, \mathrm{G})[\mathrm{Li}(\mathrm{PEG})] \mathrm{NTf}{ }_{2}$ grease at $300 \mathrm{~N}, 20 \mathrm{~Hz}$, sliding $30 \mathrm{~min}$ and room temperature.

XPS analysis. The lithium ILs, having a strong affinity with metal, could be easily adsorbed on the sliding surface, which would form an effective chemical adsorption film. Under severe friction conditions, the chemical reaction boundary lubricating film would be formed thereon to reduce friction and wear [31,32]. To further explore the chemical characteristics of the protective films, we obtained the XPS spectra of the elements typically on the worn surface lubricated with the greases. Figure 6 gives the XPS spectra of O1s, F1s, Fe2p, B1s, P2p, and N1s for the worn surface lubricated by the PEG grease and the conductive greases.

As shown in Fig. 6, the XPS peak of F1s located at $683.8 \mathrm{eV}$ was fluorine atoms bonded to metal, and the peak of Fe2p appeared at from approximately $710.6 \mathrm{eV}$ to $725.2 \mathrm{eV}$, which is assigned to $\mathrm{FeF}_{2}$ and $\mathrm{FeF}_{3}$ [33]. The O1s peak appearing at $531.2 \mathrm{eV}$ indicates that the 

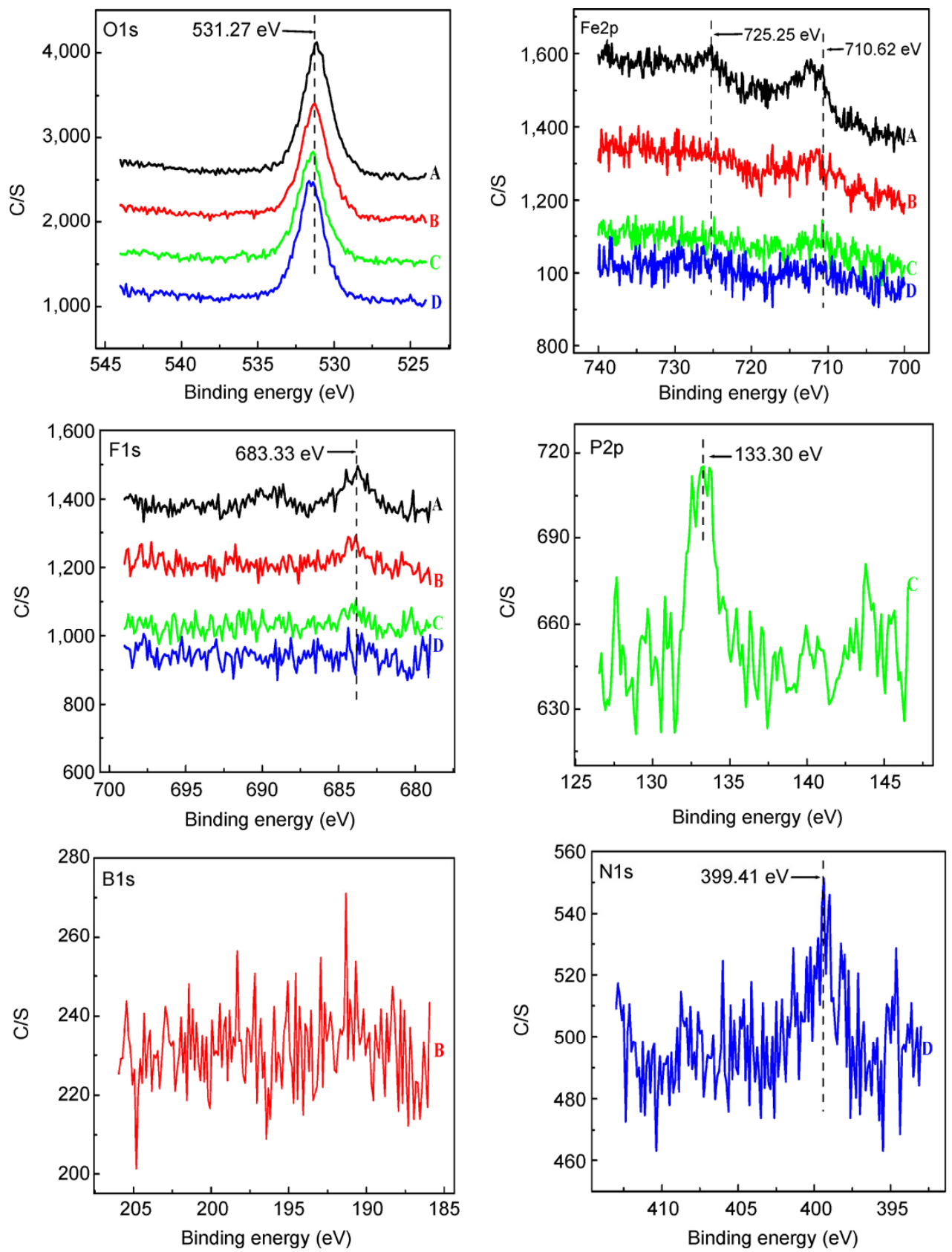

Fig. 6 XPS spectra of the typical elements of the worn surface lubricated by (A) PEG grease, (B) $[\mathrm{Li}(\mathrm{PEG})] \mathrm{BF}_{4}$ grease , (C) $[\mathrm{Li}(\mathrm{PEG})] \mathrm{PF}_{6}$ grease and $(\mathrm{D})[\mathrm{Li}(\mathrm{PEG})] \mathrm{NTf}_{2}$ grease.

worn surfaces have complex oxidation products. To further determine the type of generated oxidation products, we measured the XPS peaks of P2p, B1s, and N1s. XPS P2p spectrum at $133.3 \mathrm{ev}$ is attributed to $\mathrm{P}-\mathrm{O}$ bonding, which may generate phosphate [34]. No characteristic peaks of B1s were detected on the worn surface, so the generation of borides is uncertain. The peak of N1s corresponding to nitrogen oxide appeared at $399.4 \mathrm{eV}$ [35]. The experimental results suggest that the anion of the lithium ILs decompose to generate active atoms that react with fresh metal to form anti-scratch compounds, hence improving the friction and wear behavior.

The friction mechanism of the lithium IL greases is illustrated in Fig. 7. In combination with the resistance tests and XPS analytical results, it can be reasonably concluded that the physical adsorption and complex tribo-chemical reactions are involved in the sliding 


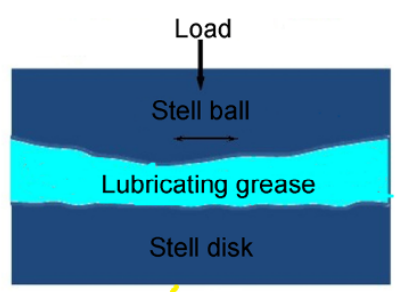

Friction mechanism

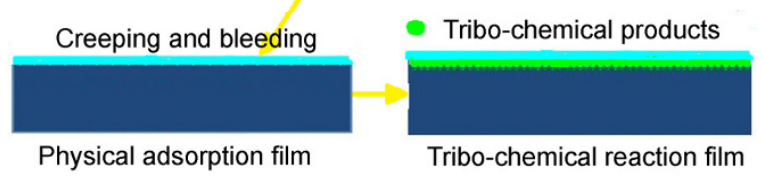

Fig. 7 Schematic of friction mechanism of the lithium ILs lubricating greases.

process for the steel/steel contacts under the boundary lubrication, which forms the surface lubricating and protective films composed of $\mathrm{FeF}_{2}, \mathrm{FeF}_{3}$, and $\mathrm{FePO}_{4}$. Thus, the lithium ILs improve friction and wear behaviors and the durability of many moving mechanical systems.

Moreover, the lithium ILs could be easily obtained with no need for separation or purification throughout the process, which makes them much cheaper than imidazolium ILs [36, 37]. It is expected that the lithium ILs could have a potential application as lubricants for lubrication industry because of their excellent tribological properties.

\section{Conclusions}

Lithium salts are highly soluble in PEG and can form lithium ILs under vigorous stirring at room temperature. The lubricating greases prepared using the lithium ILs as a base oil have high conductivities and exhibit excellent tribological performances, which is determined by the physicochemical properties and molecular structures of the lithium ILs. The selflubricating abilities of the lithium ILs offer excellent tribological behavior and a longer service life. Lithium IL greases can easily creep and bleed due to external forces and adsorb on the sliding surfaces, then a tribochemical reaction film can be formed due to the heavy load and local tribo-heat. Therefore, the boundary lubrication films, including the physical adsorption and chemical reaction films, play an important role in friction reduction and antiwear properties. In addition, the simple preparation, high solubility in synthetic oils, and excellent tribological properties of the lithium ILs make them highly advantageous as compared with neat ILs. Ultimately, it is expected that the lithium ILs could present a potential application as lubricants for the lubrication industry.

\section{Acknowledgments}

This work is supported by Hundreds Talent Program of Chinese Academy of Science.

Open Access: This article is distributed under the terms of the Creative Commons Attribution License which permits any use, distribution, and reproduction in any medium, provided the original author(s) and source are credited.

\section{References}

[1] Lugt P M, Velickov S, Tripp J H. On the chaotic behavior of grease lubrication in rolling bearings. Tribol Trans 52(5): 581-590 (2009)

[2] Lugt P M. A review on grease lubrication in rolling bearings. Tribol Trans 52(4): 470-480 (2009)

[3] Winer W O. Molybdenum disulfide as a lubricant: A review of the fundamental knowledge. Wear 10(6): 422-452 (1967)

[4] Philip C H Mitchell. Oil-soluble MO-S compounds as lubricant additives. Wear 100: 281-300 (1984)

[5] Ye C F, Liu W M, Chen Y X, Yu L G. Room-temperature ionic liquids: A novel versatile lubricant. Chem Commun 21: 2244-2245 (2001)

[6] Hagiwara R, Ito Y. Room temperature ionic liquids of alkylimidazolium cations and fluoroanions. J Fluor Chem 105 : 221-227 (2000)

[7] Holbrey J D, Seddon K R. The phase behavior of 1-alkyl3-methylimidazolium tetrafluorobprates; ionic liquids and ionic crystals. J Chem Soci Dalton Trans 13: 2133-2139 (1999)

[8] Boon J A, Levisky J A, Pflug J L, Wilkes J S. Friedel-crafts reactions in ambient-temperature molten salts. $\mathrm{J}$ Org Chem 51:480-483 (1986)

[9] LaszloJ A, Compton D L. a-Chymotrypsin catalysis in imidazolium-based ionic liquids. Biotechnol Bioeng 75: 181-186 (2001)

[10] Bose S, Wijeratne A B, Thite A, Kraus G A, Armstrong D W, Petrich J W. Influence of chiral ionic liquids on stereoselective fluorescence quenching by photoinduced electron transfer in a naproxen dyad. J Phys Chem B 113: 1082510829 (2009) 
[11] Welton T. Room-temperature ionic liquids: Solvents for synthesis and catalysis. Chem Rev 99: 2071-2083 (1999)

[12] Earle M J, Seddon K R. Ionic liquid: Green solvents for the future. Pure Appl Chem 72: 1391-1398 (2000)

[13] Zhao H. Innovative applications of ionic liquids as "green" engineering liquids. Chem Eng Commun 193: 1660-1677 (2006)

[14] Liu W M, Ye C F, Gong Q Y, Wang H Z, Wang P. Tribological performance of room-temperature ionic liquids as lubricant. Tribo Lett 13: 81-85 (2002)

[15] Cai M R, Liang Y M, Yao M H, Xia Y Q, Zhou F, Liu W M. Imidazolium ionic liquids as antiwear and antioxidant additive in poly(ethylene glycol) for steel/steel contacts. ACS Appl Mater Interfaces 2: 870-876 (2010)

[16] Jiménez A E, Bermúdez M D. Ionic liquids as lubricants for steel-aluminum contacts at low and elevated temperatures. Tribo Lett 26: 53-60 (2006)

[17] Yao M H, Liang Y M, Xia Y Q, Zhou F, Liu X Q. High-temperature tribological properties of 2-substituted imidazolium ionic liquids for $\mathrm{Si}_{3} \mathrm{~N}_{4}$-steel contacts. Tribo Lett 32: 73-79 (2008)

[18] Cai M R, Liang Y M, Zhou F, Liu W M. Anticorrosion imidazolium ionic liquids as the additive in poly(ethylene glycol) for steel/Cu-Sn alloy contacts. Faraday Discuss 156: 147-157 (2012)

[19] Xia Y Q, Sasaki S, Murakami T, Nakano M, Shi L, Wang H Z. Ionic liquid lubrication of electrodeposited nickel-Si3N4 composite coatings. Wear 262: 765-771 (2007)

[20] Feng X, Xia Y Q. Tribological properties of Ti-doped DLC coatings under ionic liquids lubricated conditions. Appl Sur Sci 258: 2433-2438 (2012)

[21] Cai M R, Liang Y M, Zhou F, Liu W M. Tribological Properties of Novel Imidazolium Ionic Liquids Bearing Benzotriazole Group as the Antiwear/Anticorrosion Additive in Poly(ethylene glycol) and Polyurea Grease for Steel/Steel Contacts. ACS Appl Mater Interfaces 3: 4580-4592 (2011)

[22] Zheng W, Mohammed A, Hines Jr L G, Xiao D, Martinez O J, Bartsch R A, Simon S L, Russina O, Triolo A, Quitevis E L. Effect of Cation Symmetry on the Morphology and Physicochemical Properties of Imidazolium Ionic Liquids. $J$ Phys Chem B 115: 6572-6584 (2011)

[23] Fan M J, Song Z H, Liang Y M, Zhou F, Liu W M. In sith formed ionic liquids in synthetic esters for signficantly improved lubrication. ACS Appl Mater Interfaces 4: 66836689 (2012)

[24] Lian Y F, Yu L G, Xue Q J. The antiwear and extreme pressure properties of some oil-water double soluble rare earth complexes. Wear 196: 188-192 (1996)
[25] Chen R J, Wu F, Li L, Xu B, Qiu X P, Chen S. Novel binary room-temperature complex system based on LiTFSI and 2-oxazolidinone and its characterization as electrolyte. J Phys Chem C 111: 5184-5194 (2007)

[26] Tamura T, Yoshida K, Hachida T, Tsuchiya M, Nakamura M, Kazue Y, Tachikawa N, Dokko K, Watanabe M. Physicochemical properties of glyme-Li salt complexes as a new family of room-temperature ionic liquids. Chem Lett 39: 753-755 (2010)

[27] Hapiot P, Lagrost C. Electrochemical Reactivity in RoomTemperature Ionic Liquids. Chem Rev 108: 2238-2264 (2008)

[28] Cai M R, Zhao Z, Liang Y M, Zhou F, Liu W M. Alkyl Imidazolium Ionic Liquids as Friction Reduction and AntiWear Additive in Polyurea Grease for Steel/Steel Contacts. Tribol Lett 40: 215-224 (2010)

[29] Lu Q M, Wang H Z, Ye C F, Liu W M, Xue Q J. Room Temperature Ionic Liquid 1-Ethyl-3-HexylimidazoliumBis(trifluoromethylsulfonyl)-Imide as Lubricant for Steel-Steel Contact. Tribol Inter 37: 547-552 (2004)

[30] Fan X Q, Xia Y Q, Wang L P, Pu J B, Chen T D, Zhang H B. Study of the Conductivity and Tribological Performance of Ionic Liquid and Lithium Greases. Tribol Lett 53: 281291 (2014)

[31] Mu Z G, Zhou F, Zhang S X, Liang Y M, Liu W M. Effect of the functional groups in ionic liquid molecules on the friction and wear behavior of aluminum alloy in lubricated aluminum-on-steel contact. Tribo Inter 38: 725-731 (2005)

[32] Kajdas C. Importance of anionic reactive intermediates for lubricant component reactions with friction surfaces. $\mathrm{Lub} \mathrm{Sci}$ 6: 203-228 (1994)

[33] Wang H Z, Lu Q M, Ye C F, Liu W M, Cui Z J. Friction and wear behaviors of ionic liquid of alkylimidazolium hexafluorophosphates as lubricants for steel/steel contact. Wear 256: 44-48 (2004)

[34] Xia Y Q, Wang S J, Zhou F, Wang H Z, Lin Y M, Xu T. Tribological properties of plasma nitrided stainless steel against SAE52100 steel under ionic liquid lubrication condition. Tribo Inter 39: 635-640 (2006)

[35] Jimenez A E, Bermudez M D, Iglesias P, Carrion F J, Martnez-Nicolas G. 1-N-alkyl-3-methylimidazolium ionic liquids as neat lubricants and lubricant additives in steelaluminium contacts. Wear 260(7-8): 766-782 (2006)

[36] Fan M J, Liang Y M, Zhou F, Liu W M. Dramatically improved friction reduction and wear resistance by in situ formed ILs. RSC Advances 2: 6824-6830 (2012)

[37] Song Z H, Fan M J, Liang Y M, Zhou F, Liu W M. Lithium-Based ILs: In Situ-Formed Lubricant Additive Only by Blending. Tribol Lett 49: 127-33 (2013) 


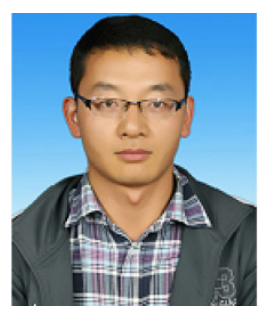

Xiaoqiang FAN. He is currently a Master-PhD student at Lanzhou Institute of Chemical Physics, Chinese Academy Science. He received his Bachelor degree in 2011

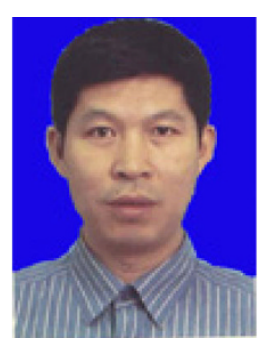

Yanqiu XIA. He got his PhD degree from Northeastern University in 1998. He joined Lanzhou Institute of Chemical Physics, Chinese Academy Science in 2008. His current

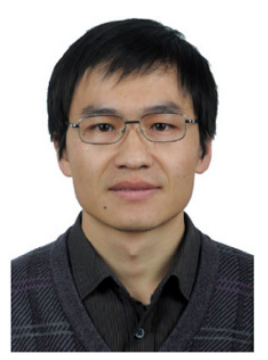

Liping WANG. He got his PhD degree from Lanzhou Institute of Chemical Physics in 2007. He is currently a group leader at Lanzhou Institute of Chemical Physics, from Qingdao University of Science \& Technology. His research interests are focused on preparation and tribological property investigation of conductive lubricating greases.

research interests cover high performance lubricants and functional materials, lubrication principle and technology. He has published more than 90 journal papers and possesses 5 patents.

Chinese Academy Science. His research interests cover solid film materials, lubricating materials and space tribology. He has published over 85 journal papers, authorized 10 patents and gained a number of national scientific awards. 